a nurse triage system would be a viable working arrangement.

Sara Ormerod Senior House Officer, All Birmingham Psychiatry Rotation, Birmingham and Solihull Mental Health NHS Trust, Trust Headquarters, Vincent Drive, Edgbaston B15 2TQ, Helen Campbell Senior House Officer, Birmingham and Solihull Mental Health NHS Trust, Gabrielle Milner Consultant Psychiatrist, Lyndon Resource Centre, Hobs Meadow, Solihull B92 8PW

\section{Goldberg and Huxley's model revisited}

We were interested that a recent editorial in The Lancet used a model of referral to specialist psychiatric services from 1980 (Peen \& Dakker, 2004). The original model (Goldberg \& Huxley, 1980) has been refined (Goldberg, 1995). One important prediction it makes is the number of adults who will be in contact with the totality of specialist mental health services. We decided to test the relevance of this model for north-east Edinburgh in 2003.

We received 1390 new referrals from the population aged 18-64 years inclusive. (Our records were hand-searched to ensure each individual was counted only once.) This is equivalent to $2.3 \%$ of the catchment population in 1 year, or 230 people per 10000 population (95\% confidence interval 220-240). The model predicts a figure of 208 adults in contact with the totality of specialist mental health services.

We conclude that the model substantially underestimated the utilisation of specialist psychiatric services. It would take a great deal more work to calculate the variance; we would have to add to the patients newly referred, patients already known to our own service, services for the elderly, NHS psychotherapy, and clinics for people with alcohol, drug and eating problems.

We do not know to what extent our findings can be generalised. We only hope that those who purchase general adult psychiatric services are not doing so on the basis of this model.

GOLDBERG, D. (1995) Epidemiology of mental disorders in primary care settings. Epidemiologic Reviews, 17, 182-190.

GOLDBERG, D. \& HUXLEY, P. (1980) Mental Illness in the Community: The Pathway to Psychiatric Care London: Tavistock Publications.

PEEN, J. \& DAKKER, J. (2004) Is urbanicity an environmental risk-factor for psychiatric disorders? The Lancet, 363, 2012-2013.

Treasa O'Sullivan Specialist Registrar, Roya dinburgh Hospital, Amanda Cotton Senior House Officer, Royal Edinburgh Hospital, *Allan Scott Consultant Psychiatrist, Andrew Duncan Clinic, Royal Edinburgh Hospital, Morningside Terrace, Edinburgh EH10 5HF

\section{The NHS International Fellowship Scheme}

The NHS International Fellowship Scheme (Khan, 2004) is discriminatory against UK trainees and non-consultant career grade (NCCG) psychiatrists. Those who choose to come to the UK and train for membership of the Royal College of Psychiatrists should feel aggrieved.

Some of the members of our College have valuable NCCG experience. Unfortunately, European legislation does not permit any NCCG experience to be counted towards the Certificate of Completion of Specialist Training (CCST). In contrast many from overseas can get on the specialist register without any UK experience.

Reportedly, these NHS international fellows are experienced psychiatrists with overseas qualifications. Goldberg (2004) mentions strict selection criteria but what evidence do we have of accreditation of training from countries where NHS international fellows are recruited? Does their training reflect the standards and strict time limits set for post membership training in the UK? This accreditation seems to be a flexible paper exercise. Also, we must not forget that psychiatric higher training is not about management of mental illnesses alone.

Our Royal College should not forget NCCGs, who have filled a gap in NHS psychiatry. The Postgraduate Medical Education Training Board is likely to bring a change. Our college should pre-empt this and show leadership by forward thinking and acknowledge NCCG experience of their members towards CCST.

Overseas doctors should be welcomed. However, they should undergo a period of specialist registrar training in the UK commensurate with their experience. Following this training they should be appointed as consultants in open competition against home grown trainees.

GOLDBERG, D. (2004) The NHS International Fellowship Scheme in Psychiatry. Psychiatric Bulletin, 28, 433-434

KHAN, M. M. (2004) The NHS International Fellowship Scheme in Psychiatry: robbing the poor to pay the rich? Psychiatric Bulletin, 28, 435-437.

Tayyeb A. Tahir Specialist Registrar in Psychiatry Whitchurch Hospital, Cardiff CF14 7XB 